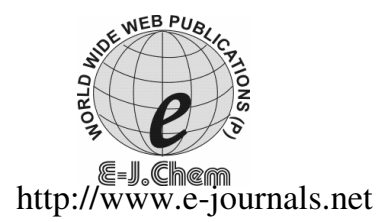

ISSN: 0973-4945; CODEN ECJHAO

E-Journal of Chemistry 2009, 6(S1), S247- S253

\title{
Bentonite Clay K-10 as an Efficient Reagent for the Synthesis of Quinoxaline Derivatives at Room Temperature
}

\author{
ALIREZA HASANINEJAD* ${ }^{*}$, ABDOLKARIM ZARE ${ }^{\S}$, \\ MOHSEN SHEKOUHY and AHMAD REZA MOOSAVI-ZARE ${ }^{\S}$ \\ Department of Chemistry, Faculty of Sciences, \\ Persian Gulf University, Bushehr 75169, Iran. \\ ${ }^{\S}$ Department of Chemistry, \\ Payame Noor University (PNU), Iran. \\ ahassaninejad@yahoo.com
}

Received 22 August 2008; Accepted 5 October 2008

\begin{abstract}
Bentonite clay K-10 acts as an efficient reagent for the preparation of quinoxaline derivatives via the condensation of aryl and alkyl 1,2-diamines with $\alpha$-diketones in ethyl alcohol as a green media at room temperature. Using this method, the title compounds are produced in high to excellent yields and short reaction times.
\end{abstract}

Keywords: Bentonite clay K-10, Quinoxaline, 1,2-Diamine, $\alpha$-Diketone, Green chemistry.

\section{Introduction}

Quinoxaline derivatives have attracted much interest because of possessing various biological activities such as antimycobacterial ${ }^{1,2}$, tranquilizing ${ }^{3}$, anthelmintic ${ }^{4}$, antidepressant ${ }^{5}$, and antitumor properties ${ }^{6,7}$, etc. Several kinds of synthetic routes toward quinoxalines have been developed, including heteroannulation of nitroketene $N, S$ aryliminoacetals with $\mathrm{POCl}_{3}{ }^{8}$, cyclization of $\alpha$-arylimino oximes of $\alpha$-dicarbonyl compounds ${ }^{9}$, bi-catalyzed oxidative coupling of epoxides with ene-1,2-diamines ${ }^{10}$, and from $\alpha$-hydroxy ketones via a tandem oxidation process using $\mathrm{Pd}(\mathrm{OAc})_{2}$ or $\mathrm{RuCl}_{2}-\left(\mathrm{PPh}_{3}\right)_{3^{-}}$ TEMPO $^{11}$. However, the most common method for the preparation of quinoxalines is the condensation of 1,2-diamines with $\alpha$-diketones. For this transformation several reagents such as ceric(IV) ammonium nitrate ${ }^{12}$, iodine in $\mathrm{DMSO}^{13}$, sulfamic acid ${ }^{14}, \mathrm{Yb}(\mathrm{OTf})_{3}{ }^{15}$, oxalic acid ${ }^{16}$, $o$-iodoxybenzoic acid ${ }^{17}, \mathrm{H}_{6} \mathrm{P}_{2} \mathrm{~W}_{18} \mathrm{O}_{62} \cdot 24 \mathrm{H}_{2} \mathrm{O}^{18}$, zeolite ${ }^{19}, \mathrm{KHSO}_{4}{ }^{20}$, and $\mathrm{CuSO}_{4} \cdot 5 \mathrm{H}_{2} \mathrm{O}^{21}$ have been applied. It is worth noting that the methods that have been established for the preparation of quinoxaline derivatives are associated with one or more of the following drawbacks: 
(i) the need for anhydrous conditions, (ii) harsh reaction conditions, (iii) the use of expensive reagents, (iv) long reaction time, (v) moderate yield, and (iv) no agreement with the green chemistry protocols. Moreover, some methods are not efficient when aryl 1,2-diamines with electron-withdrawing substituents are used in the condensation reaction. Therefore, development of an efficient, safe, cheap, and environmentally friendly reagent for the synthesis of quinoxalines is desirable.

Clay is a very cheap, commercially available, green and heterogeneous reagent which has been used in various organic transformations such as Biginelli condensation ${ }^{22}$, BaeyerVilliger oxidation of ketones ${ }^{23}$, anti-Markovnikov hydroamination of $\alpha, \beta$-ethylenic compounds $^{24}$, epoxidation of alkenes and hydroxylation of alkanes ${ }^{25}$, synthesis of $1,2,3,4-$ tetrahydrocarbazole and indoles ${ }^{26}$, Friedel-Crafts type benzylation reactions ${ }^{27}$, ring opening of epoxides with thiols ${ }^{28}$, synthesis of bisphthalimides ${ }^{29}$, synthesis of 2-aryl-1-arylmethyl$1 H$-1,3-benzimidazoles ${ }^{30}$, and Michael reaction of amines ${ }^{31}$, etc.

Considering the above subjects, and also in continuation of our previous studies on development of the efficient and environmentally benign synthetic methodologies in organic synthesis ${ }^{16,32-37}$, we report here a simple, highly efficient, very cheap and green method for the synthesis of quinoxaline derivatives via the condensation of aryl and alkyl 1,2-diamines with $\alpha$-diketones in the presence of bentonite clay K-10 under extremely mild reaction conditions (Scheme 1). This method has none of the above mentioned disadvantages at all.

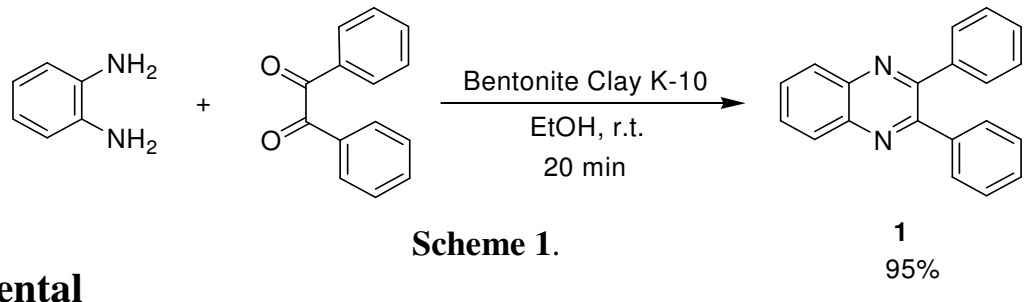

\section{Experimental}

All chemicals were purchased from Merck, Fluka or Acros Chemical Companies. All products are known and their structures were identified by comparison of their melting points and spectral data with those in the authentic samples. The ${ }^{1} \mathrm{H}$ NMR $(250 \mathrm{MHz})$ and ${ }^{13} \mathrm{C}$ NMR $(62.5 \mathrm{MHz})$ were run on a Bruker Avance DPX-250, FT-NMR spectrometer, $\delta$ in ppm. Mass spectra were recorded on a Shimadzu GC MS-QP 1000 EX apparatus. Microanalyses were performed on a Perkin-Elmer 240-B microanalyzer. Melting points were recorded on a Büchi B-545 apparatus in open capillary tubes.

\section{General procedure for the preparation of quinoxaline derivatives}

To a mixture of $\alpha$-diketone ( $1 \mathrm{mmol})$, bentonite clay K-10 $(2.5 \mathrm{~g})$ and $\mathrm{EtOH}(20 \mathrm{~mL})$ in a $50 \mathrm{~mL}$ round bottomed flask, 1,2-diamine $(1 \mathrm{mmol})$ was added, and the resulting mixture was stirred at room temperature for the times reported in Table 3. Afterward, the reaction mixture was poured on a Celite pad and washed with warm EtOH $(30 \mathrm{~mL})$. The mixture was concentrated to $5 \mathrm{~mL}$ and to it $\mathrm{H}_{2} \mathrm{O}(10 \mathrm{~mL})$ was added, and was allowed to stand at room temperature for $1 \mathrm{~h}$. During this time, crystals of the pure product were formed which collected by filtration. After isolation of the product, the remaining reagent was dried and used for the next run under identical reaction conditions. It is noteworthy that the reagent was reused for 5 times without any significant changes in the yields and the reaction times. 


\section{Selected spectral data of the products}

\section{2,3-Diphenylquinoxaline (1)}

White solid; m.p. $129-130{ }^{\circ} \mathrm{C}$ (Lit. ${ }^{16}$ m.p. $\left.130-131{ }^{\circ} \mathrm{C}\right) ;{ }^{1} \mathrm{H}$ NMR $\left(\mathrm{CDCl}_{3}\right): \delta$ 7.29-7.33 (m, $6 \mathrm{H}), 7.51(\mathrm{~m}, 4 \mathrm{H}), 7.77(\mathrm{~m}, 2 \mathrm{H}), 8.21(\mathrm{~m}, 2 \mathrm{H}) ;{ }^{13} \mathrm{C} \mathrm{NMR}\left(\mathrm{CDCl}_{3}\right): \delta 128.1,128.7,129.1$, 129.9, 131.0, 139.6, 141.7, 153.2; MS (m/z): $282\left(\mathrm{M}^{+}\right)$; Anal. calcd. for $\mathrm{C}_{20} \mathrm{H}_{14} \mathrm{~N}_{2}: \mathrm{C}, 85.08$; H, 5.00; N, 9.92. Found: C, 85.25; H, 5.26; N, 9.74.

\section{9,10-Dimethylacenaphtho[1,2-b]quinoxaline (10)}

Yellow solid; m.p. 303-305 ${ }^{\circ} \mathrm{C}$ (Lit. ${ }^{16}$ m.p. $\left.304-306{ }^{\circ} \mathrm{C}\right) ;{ }^{1} \mathrm{H}$ NMR $\left(\mathrm{CDCl}_{3}\right): \delta 2.51(\mathrm{~s}, 6 \mathrm{H})$, $7.78(\mathrm{~m}, 2 \mathrm{H}), 7.89(\mathrm{~s}, 2 \mathrm{H}), 8.03(\mathrm{~m}, 2 \mathrm{H}), 8.34(\mathrm{~m}, 2 \mathrm{H}) ;{ }^{13} \mathrm{C} \mathrm{NMR}\left(\mathrm{CDCl}_{3}\right): \delta 20.3,121.5$, 127.8, 128.0, 128.6, 128.9, 129.1, 139.5, 140.00, 148.5, 153.3; MS (m/z): $282\left(\mathrm{M}^{+}\right)$; Anal. calcd. for $\mathrm{C}_{20} \mathrm{H}_{14} \mathrm{~N}_{2}$ : C, 85.08; H, 5.00; N, 9.92. Found: C, 85.23; H, 5.21; N, 10.17 .

\section{2,3-Di p-tolylbenzo[g]quinoxaline (14)}

Yellow solid; m.p. $195-197{ }^{\circ} \mathrm{C}$ (Lit. ${ }^{12}$ m.p. $\left.198{ }^{\circ} \mathrm{C}\right) ;{ }^{1} \mathrm{H}$ NMR $\left(\mathrm{CDCl}_{3}\right): \delta 2.35(\mathrm{~s}, 6 \mathrm{H}), 7.16$ $(\mathrm{d}, 4 \mathrm{H}, J 8.0 \mathrm{~Hz}), 7.45-7.50(\mathrm{~m}, 6 \mathrm{H}), 8.05(\mathrm{~m}, 2 \mathrm{H}), 8.62(\mathrm{~s}, 2 \mathrm{H}) ;{ }^{13} \mathrm{C} \mathrm{NMR}\left(\mathrm{CDCl}_{3}\right): \delta 22.3$, 126.2, 127.1, 128.3, 128.7, 129.5, 134.2, 136.3, 138.2, 139.6, 153.9; MS (m/z): $360\left(\mathrm{M}^{+}\right)$; Anal. calcd. for $\mathrm{C}_{26} \mathrm{H}_{20} \mathrm{~N}_{2}$ : C, 86.64; H, 5.59; N, 7.77. Found: C, 86.85; H, 5.78; N, 8.01.

\section{Results and Discussion}

As previously mentioned, clay has been applied as a very inexpensive reagent in various organic transformations ${ }^{22-31}$. This subject as well as high importance of quinoxaline derivatives encouraged us to use clay as reagent for the preparation of quinoxalines from 1,2-diamines and $\alpha$-diketones. Thus, firstly we studied condensation of benzene-1,2-diamine $(1 \mathrm{mmol})$ with benzil $(1 \mathrm{mmol})$ in the presence of different amounts of bentonite clay $\mathrm{K}-10$ in $\mathrm{EtOH}(20 \mathrm{~mL})$ at room temperature to provide compound $\mathbf{1}$ (Scheme 1). The results are summarized in Table 1. As it can be seen from Table 1, the best results were obtained when 2.5 g clay was applied.

Table 1. The condensation of benzene-1,2-diamine $(1 \mathrm{mmol})$ with benzil $(1 \mathrm{mmol})$ in the presence of different amounts of bentonite clay K-10 in EtOH $(20 \mathrm{~mL})$ at room temperature.

\begin{tabular}{cccc}
\hline Entry & Amount of clay, $g$ & Time, $\min$ & Yield $^{\mathrm{a}}, \%$ \\
\hline 1 & 0.5 & 720 & 38 \\
2 & 1 & 120 & 43 \\
3 & 1.5 & 90 & 65 \\
4 & 2 & 60 & 93 \\
5 & 2.5 & 20 & 95 \\
6 & 3 & 20 & 95 \\
\hline
\end{tabular}

${ }^{a}$ Isolated yield.

In order to choose the appropriate solvent for the reaction, the synthesis of quinoxaline $\mathbf{1}$ was examined in different solvents (Table 2). As Table 2 indicates, higher yield and shorter reaction time were obtained in $\mathrm{EtOH}$.

To assess the generality and scope of our method, various aromatic and aliphatic 1,2diamines were reacted with structurally diverse $\alpha$-diketones. The results are displayed in Table 3. As it is shown in Table 3, all reactions proceeded efficiently and the corresponding quinoxalines were obtained in high to excellent yields and short reaction times. 
Table 2. The effect of different solvents on the reaction of benzene-1,2-diamine with benzil in the presence of bentonite clay K-10 at room temperature.

\begin{tabular}{llcc}
\hline Entry & Solvent & Time, min & Yield $^{\mathrm{a}}, \%$ \\
\hline 1 & EtOH & 20 & 95 \\
2 & $\mathrm{MeOH}$ & 30 & 91 \\
3 & $\mathrm{H}_{2} \mathrm{O}$ & 120 & Trace \\
4 & $\mathrm{CHCl}_{3}$ & 30 & 87 \\
5 & $\mathrm{CH}_{2} \mathrm{Cl}_{2}$ & 30 & 82 \\
6 & $\mathrm{MeCN}$ & 35 & 92 \\
7 & $\mathrm{THF}$ & 30 & 89 \\
\hline \multicolumn{3}{c}{${ }^{\text {a Isolated yield }}$}
\end{tabular}

Table 3. Synthesis of quinoxalines via the condensation of 1,2-diamines with $\alpha$-diketones using bentonite clay $\mathrm{K}-10$ at room temperature.

M.p. ${ }^{\circ} \mathrm{C}$
(Lit.)




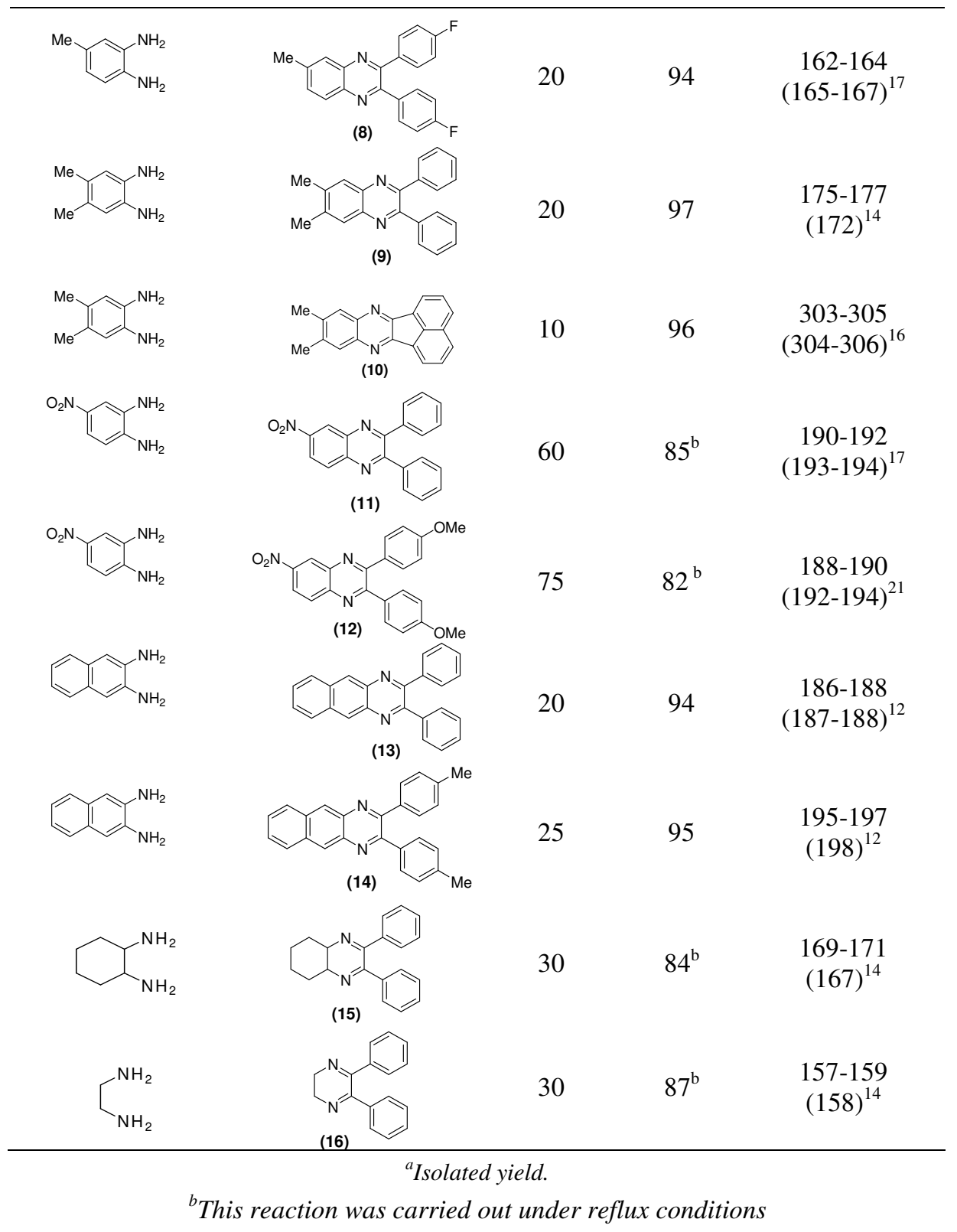

The effect of electron-releasing and electron-withdrawing substituents on the aromatic ring of aryl 1,2-diamines on the reaction was investigated. The results showed that electron-releasing groups had no significant effect on the reaction results (Table 3, compounds 5-10); however, electron-withdrawing substituents decreased the yields and increased the reaction times (Table 3, compounds 11 and 12). In these cases, harsher reaction conditions were also needed. Moreover, it has been observed that the electronic properties of the aromatic ring of $\alpha$-diketones had negligible effect on the yields and the reaction times. Aliphatic 1,2- diamines afforded the corresponding quinoxalines in high yields but in harsher reaction conditions (Table 3, compounds $\mathbf{1 5}$ and 16). 


\section{Conclusions}

In summary, this presented procedure provides a new methodology for the preparation of quinoxalines from aryl 1,2-diamines and $\alpha$-diketones. The advantages of this method are extremely mild reaction conditions, short reaction times, high yields, efficiency, generality, low cost, simple experimental and isolation procedures, and compliance with the green chemistry protocols.

\section{Acknowledgement}

We thank Persian Gulf University and Payame Noor University (PNU) Research Councils for the financial support of this work.

\section{References}

1. Waisser K, Odlerova Z, Beckert R and Mayer R, Pharmazie, 1989, 44, 234.

2. Seitz L E, Suling W J and Reynolds R C, J Med Chem., 2002, 45, 5604.

3. Osdene T S, US Patent 3 185 688, 1965; Chem Abstr., 1965, 46, 3191.

4. Sakata G, Makino K and Karasawa Y, Heterocycles, 1988, 27, 2481, and references cited therein.

5. Sarges R, Howard H R, Browne R C, Label L A and Seymour P A, J Med Chem., 1990, 33, 2240.

6. Hazeldine S T, Polin L, Kushner J, Paluch J, White K, Edelstein M, Palomino E, Corbett T H and Horwitz J P, J Med Chem., 2001, 44, 1758.

7. Hazeldine S T, Polin L, Kushner J, White K, Bouregeois N M, Crantz B, Palomino E, Corbett T H and Horwitz J P, J Med Chem., 2002, 45, 3130.

8. Venkatesh C, Singh B, Mahata P K, Ila H and Junjappa H, Org Lett., 2005, 7, 2169.

9. Xekoukoulotakis N P, Hadjiantonious M C P and Maroulis A J, Tetrahedron Lett., 2000, 41, 10299.

10. Antoniotti S and E. Donach, Tetrahedron Lett., 2002, 43, 3971.

11. Robinson R S and Taylor R J K, Synlett, 2005, 1003.

12. More S V, Sastry M N V and Yao C-F, Green Chem., 2006, 8, 91.

13. Bhosale R S, Sarda S R, Ardhapure S S, Jadhav W N, Bhusare S R and Pawar R P, Tetrahedron Lett., 2005, 46, 7183.

14. Darabi H R, Mohandessi S, Aghapoor K and Mohsenzadeh F, Catal Commun., 2007, 389.

15. Wang L, Liu J, Tian H and Qian C, Synth Commun., 2004, 34, 1349.

16. Hasaninejad A, Zare A, Mohammadizadeh M R and Shekouhy M, ARKIVOC, 2008, 13, 28.

17. Heravi M M, Bakhtiari K, Tehrani M H, Javadi N M and Oskooie $\mathrm{H} \mathrm{A}$, ARKIVOC, 2006, 16, 16.

18. Heravi M M, Bakhtiari K, Bamoharram F F and Tehrani M H, Monatsh Chem., 2007, 138, 465.

19. Gopaland D V and Subrahmanyam M, Catal Commun., 2001, 219.

20. Oskooie H A, Heravi M M, Bakhtiari K and Taheri S, Monatsh Chem., 2007, 138, 875 .

21. Heravi M M, Taheri S, Bakhtiari K and Oskooie H A, Catal Commun., 2007, 211.

22. Singh V, Sapehiyia V, Srivastava V and Kaur S, Catal Commun., 2006, 571.

23. Kawabata T, Fujisaki N, Shishido T, Nomura K, Sano T and Takehira K, J Mol Catal A: Chem., 2006, 253, 279. 
24. Joseph T, Shanbhag G V, Sawant D P and Halligudi S B, J Mol Catal A: Chem., 2006, 250, 210.

25. Bahramian B, Mirkhani V, Moghadam M and Tangestaninejad S, Catal Commun., 2006, 289.

26. Dhakshinamoorthy A and Pitchumani K, Appl Catal A: General, 2005, 292, 305.

27. Choudhary V R, Jha R and Narkhede V S, J Mol Catal A: Chem., 2005, 239, 76.

28. Mojtahedi M M, Ghasemi M H, Abaee M S and Bolourtchian M, ARKIVOC, 2005, 15, 68.

29. Habibi D and Marvi O, ARKIVOC, 2006, 13, 8.

30. Perumal S, Mariappan S and Selvaraj S, ARKIVOC, 2004, 8, 46.

31. Shaikh N S, Deshpande V H and Bedekar A V, Tetrahedron, 2001, 57, 9045.

32. Hasaninejad A, Parhami A, Zare A, Khalafi-Nezhad A, Nasrolahi Shirazi A and Moosavi Zare A R, Polish J Chem., 2008, 82, 565.

33. Khalafi-Nezhad A, Parhami A, Zare A, Moosavi Zare A R, Hasaninejad A and Panahi F, Synthesis, 2008, 617.

34. Zare A, Hasaninejad A, Beyzavi M H, Parhami A, Moosavi Zare A R, KhalafiNezhad A and Sharghi H, Can J Chem., 2008, 86, 317.

35. Zare A, Hasaninejad A, Khalafi-Nezhad A, Parhami A and Moosavi Zare A R, J Iran Chem Soc., 2008, 5, 100.

36. Hasaninejad A, Zare A, Sharghi H and Shekouhy M, ARKIVOC, 2008, 11, 64.

37. Hasaninejad A, Zare A, Jafari F and Moosavi-Zare A R, E Journal of Chemistry, $2009,6,459$. 


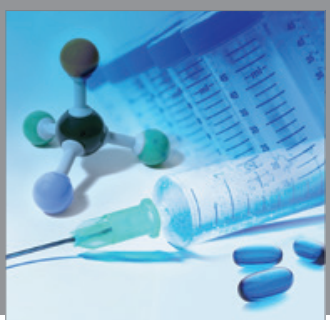

International Journal of

Medicinal Chemistry

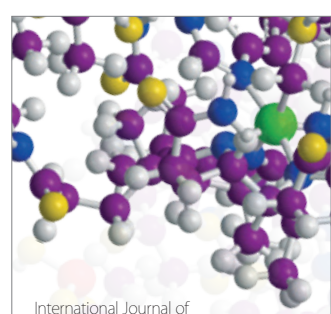

Carbohydrate Chemistry

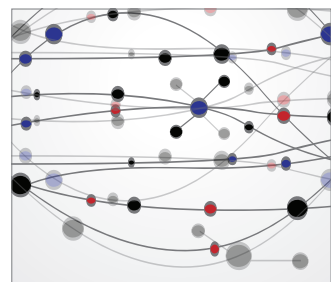

The Scientific World Journal
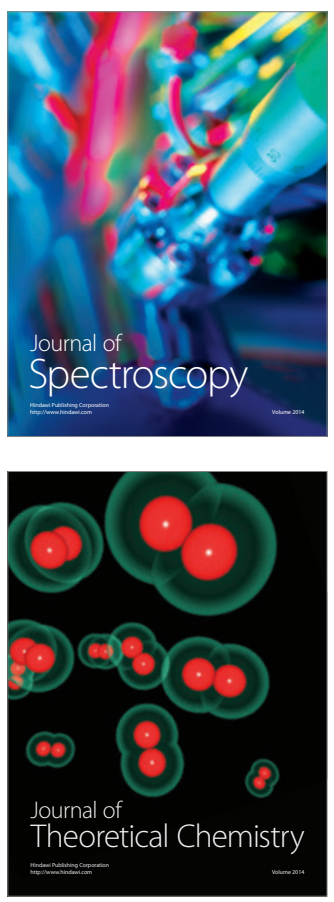
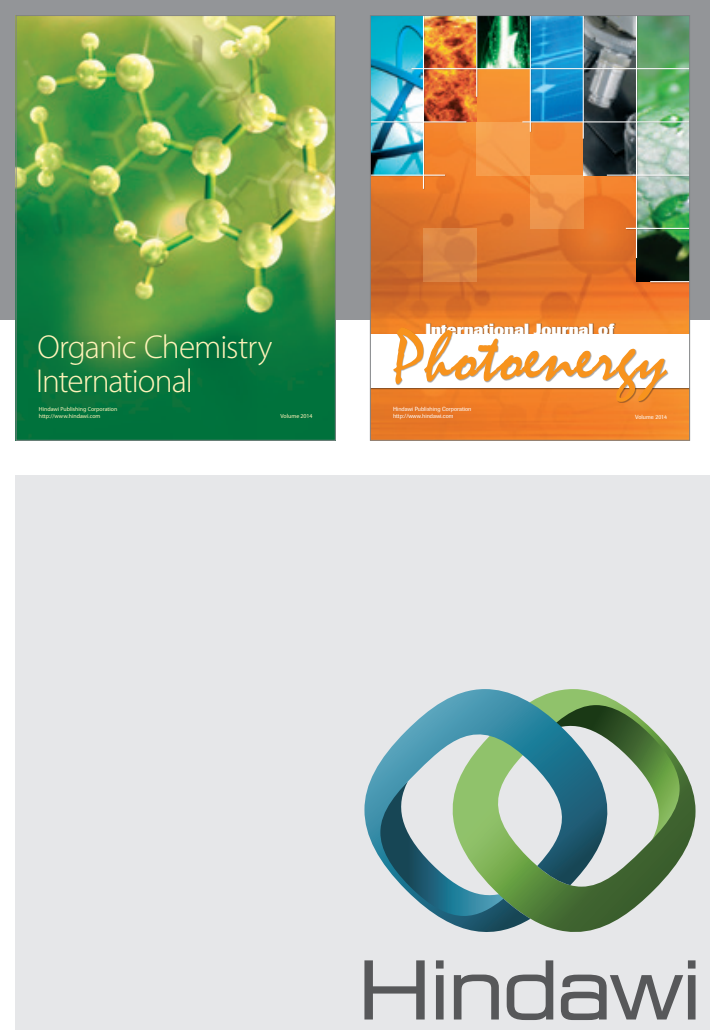

Submit your manuscripts at

http://www.hindawi.com
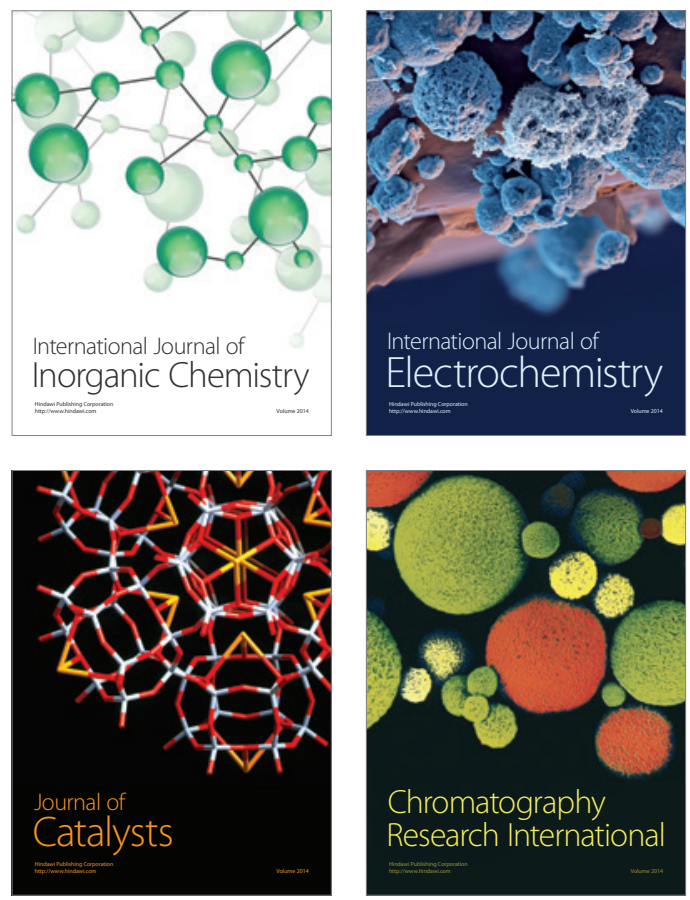
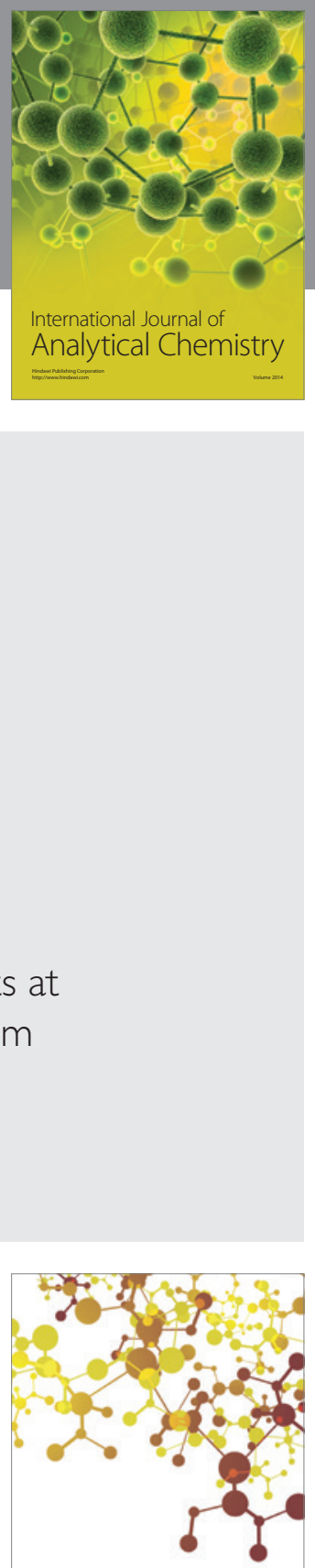

Journal of

Applied Chemistry
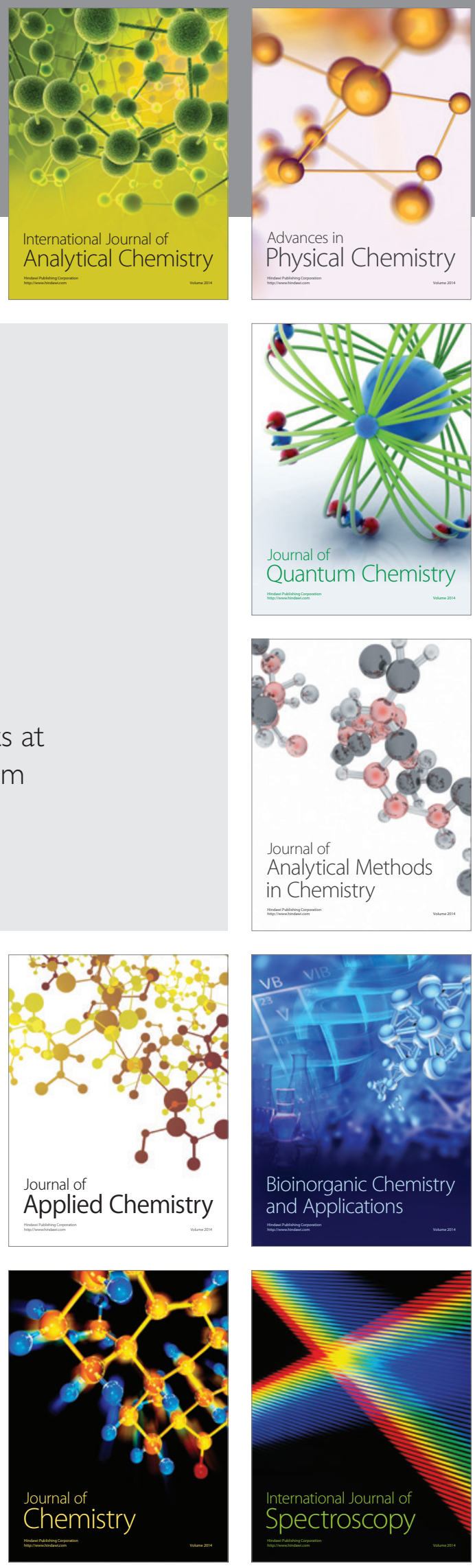